\title{
Experiencing organ donation: feelings of relatives after consent ${ }^{1}$
}

\author{
Marli Elisa Nascimento Fernandes² \\ Zélia Zilda Lourenço de Camargo Bittencourt ${ }^{3}$ \\ Ilka de Fátima Santana Ferreira Boin ${ }^{4}$
}

Objective: to identify experiences and feelings on the organ donation process, from the perspective of a relative of an organ donor in a transplant unit. Method: this was exploratory research using a qualitative approach, performed with seven family members of different organ donors, selected by a lottery. Sociodemographic data and the experiences regarding the donation process were collected through semi-structured interviews. The language material was transcribed and submitted to content analysis. Results: poor sensitivity of the medical staff communicating the relative's brain death - the potential donor - and the lack of socio-emotional support prior to the situation experienced by the family was highlighted by participants. Conclusions: the study identified the need to provide social-emotional support for families facing the experience of the organ donation process. From these findings, other care and management practices in health must be discussed to impact the strengthening of the family ties, post-donation, as well as the organ procurement indexes.

Descriptors: Family; Tissue Donors; Humanization of Assistance; Health Policy, Planning and Management.

\footnotetext{
${ }^{1}$ Paper extracted from doctoral dissertation "Percepção das famílias de doadores de órgãos sobre o processo de doação", presented to Faculdade de Ciências Médicas, Universidade Estadual de Campinas, Campinas, SP, Brazil.

2 Doctoral student, Faculdade de Ciências Médicas, Universidade Estadual de Campinas, Campinas, SP, Brazil. Social Worker, Hospital de Clínicas, Universidade Estadual de Campinas, Campinas, SP, Brazil.

${ }^{3} \mathrm{PhD}$, Professor, Faculdade de Ciências Médicas, Universidade Estadual de Campinas, Campinas, SP, Brazil.

${ }^{4}$ PhD, Full Professor, Faculdade de Ciências Médicas, Universidade Estadual de Campinas, Campinas, SP, Brazil.
}

Corresponding Author:

Marli Elisa Nascimento Fernandes

Universidade Estadual de Campinas. Faculdade de Ciências Médicas

Rua Vital Brasil, 251

Cidade Universitária Zeferino Vaz

CEP: 13083-888, Campinas, SP, Brasil

E-mail: marli.eliza@terra.com.br
Copyright () 2015 Revista Latino-Americana de Enfermagem This is an Open Access article distributed under the terms of the Creative Commons Attribution Non-Commercial License (CC BY-NC).

This license lets others distribute, remix, tweak, and build upon your work non-commercially, and although their new works must also acknowledge you and be non-commercial, they don't have to license their derivative works on the same terms. 


\section{Introduction}

The donation of organs for transplantation is a complex process involving a set of procedures managed by the National Transplant System - Ministry of Health in Brazil, and regulated by laws and protocols that aim for effective actions related to procurement services, in order to increase organ and tissue donation for transplantation ${ }^{(1)}$.

Recently, organ donation rates have grown in several countries, however, despite this fact, the disproportion between the number of donations and the number of patients on the waiting list for an organ is of global concern $^{(2)}$. The Spanish model of organ procurement is considered to achieve the best rate - it stands out with 35.1 donors per million population ${ }^{(3)}$.

The effective donor rate in Brazil (14 per million population - pmp) was lower than expected in 2014, not reaching the target established by the Brazilian Association of Organ Transplantation - ABTO (15 pmp). The positive data in our country results from the continuous growth in potential donor detection rate; however, a decrease in the effective rate of donation occurred, as the national rate of family refusal increased to $46 \%{ }^{(4-5)}$.

The donation process for transplantation involves a protocol to be followed throughout the national territory: identification of patients with the clinical criteria of brain death (BD); diagnosis of BD; clinical and laboratory evaluation; maintenance of the potential donor; and, family interview ${ }^{(2,4)}$. Because of this complexity, interdisciplinary team performance involving medicine, nursing, social work and laboratory technicians is required.

Actions aimed at hhumanization of care are recommended in the healthcare field, emphasizing the ethical dimension in the relationship between patients and professionals. Thus, welcoming is recommended as part of caring, and is performed by social worker professionals with the families, whose loved ones are in intensive care units. During this process, the social worker identifies the social conditions of families, which provides social assistance support, acting as a link between procurement team members to ensure that the family has better comprehension of information(6-7).

Ethics and humanization are essential for the procurement team during the donation process, as well as a family approach that is configured with respect to pain limits, loss and family decisions. Nurses and social workers have a closer relationship with the family during hospitalization, and are, in most cases, the people responsible for the family interview for donation consent ${ }^{(7-9)}$.

In the context of the donation process, nursing professionals, who experience the suffering of the relatives, provide information that clarifies doubts regarding the diagnostic and clinical status of potential donors from the descriptions in the medical records, prescriptions and tests results ${ }^{(9)}$.

The Unified Health System (UHS-SUS) recommends that humanization of care in the hospital should involve multidisciplinary team actions; because the relationship between staff and family is reflected in the family refusal rates in the process of organ procurement within the national transplant system ${ }^{(1,7)}$.

Studies on the impact on donation, as well as the consent of relatives for organ donation, revealed that social workers and nurses are those most concerned about the care given to the family, among the professionals involved in the process ${ }^{(8,10)}$.

Issues related to the family interview for the donation consent, and concerns about the brain death diagnostic criteria, were found in literature ${ }^{(2,11)}$. Families of potential donors, during visits to their loved ones in the hospital, observe the presence of a heartbeat, a flushed and warm body, and often expressed doubts about the brain death of their relative $\mathrm{e}^{(8,10-12)}$.

The family experience about the donation process has been explored by several authors, emphasizing factors that negatively interfere with family consent for organ donation ${ }^{(13)}$.

Since this is a complex issue, the Brazilian public policies focused on centrality of family as a social core, determining the legislation for organ donation, informed consent must be requested and signed by the family in duplicate, in front of two witnesses who were present at the confirmation of death(4).

According the afore-mentioned aspects permeating the organ donation issue, the objective of this research was to identify the experiences and feelings of the family members of organ donors related to unidentified peculiarities by procurement teams during the process of organ donation for transplants, and its effects on the population and public health policy.

\section{Method}

This exploratory study using a qualitative approach was conducted during the period of March of 2012 to 
June of 2013, using the organ donors' database of the Organ Procurement Organization (OPO) for transplants of Hospital Clinics (HC), State University of Campinas (Unicamp). The team consisted of a social worker, nurse, physician and psychologist. Twelve families members living in the Campinas / SP metropolitan area were selected from the database for the study. Family members were invited by telephone to participate in an interview, which was scheduled according to their availability. Five families refused to participate, indicating a lack of emotional capability. Seven families from different donors were interviewed, using a semistructured questionnaire containing demographic data with the following variables: sex, age in years, skin color, educational level, origin, family relationship with the donor, interview time after the consent for donation, and questions about the experience of the donation process. With the exception of two interviews that were performed at the hospital, the others occurred in the donor family's home, more than two months after they consented for organ donation. The interviews were recorded with the authorization of the participants who signed the Terms of Free and Informed consent; they received copies and an informative summary of the research.

Interviews were transcribed and analyzed according to the qualitative methodological framework of content analysis $^{(14)}$; in the pre-analysis, the material was read to identify categories that clustered into two central themes: experiences on consent for organ donation, and, feelings of family members after providing authorization. The ethical aspects in the various stages of the research were respected, according to Resolution 466/12 of CONEP - National Research Ethics Council and the National Health Council, safeguarding anonymity, confidentiality and the privacy of family members being interviewed, who were identified by the letter $(F)$ followed by the serial number of the interviews. The research was approved by the Research Ethics Committee of the Faculty of Medical Sciences, Campinas, Protocol 1059 / 2011CAAE: 0958.0.146.000-11.

\section{Results}

The data characterizing the research participants are presented in Table 1.

Table 1 - Distribution of the characteristics of the responding family members. Campinas, SP, Brazil, 2012

\begin{tabular}{|c|c|c|c|c|c|c|c|}
\hline Family Member & (F1) & (F2) & (F3) & (F4) & (F5) & (F6) & (F7) \\
\hline Sex & $M$ & $M$ & $M$ & $M$ & $M$ & $\mathrm{~F}^{*}$ & $M$ \\
\hline Age (Years) & 26 & 64 & 31 & 25 & 39 & 45 & 56 \\
\hline Skin color & White & White & Black & White & Black & White & White \\
\hline Educational level & $\mathrm{HS}^{\dagger}$ & $\mathrm{ES}^{\ddagger}$ & $\mathrm{HS}$ & HS & HS & ES & ES \\
\hline Place of origin & Campinas & Cosmópolis & Piracicaba & Campinas & Sumaré & Campinas & Artur Nogueira \\
\hline Kinship & Son & Father & Partner & Father & Brother & Mother & Father \\
\hline Time after donation & 12 Months & 5 Months & 6 Months & 14 Months & 15 Months & 13 Months & 13 Months \\
\hline
\end{tabular}

Most of those who agreed to participate in the interview were men, with ages ranging from 25 - 64 years, of low-educated families, and with the kinship to the donor of either spouse, brother or parents.

To understand the social dynamics and the relationships established between the participating subjects, and their contexts during the donation process, the qualitative data were divided into two themes: experiences regarding providing consent for organ donation and feelings after providing consent for organ donation.

\section{Experiences regarding providing consent for organ donation}

Following the communication of the diagnosis of brain death of a relative, the findings indicated a lack of understanding by the medical staff to predict the impact generated within the family who had just lost a loved one: [...] it was very fast, because the person receives the news of the brain death, I think the physician should not talk right away about organ donation. At that time I had no strength, I would not listen more, I began to scream ... then the physician 
stopped talking (F3). [...] I was outraged; I did not find it right, my mother is there, on the bed, it is a bad time and everyone there is talking about donation. I think what most impressed me, I did not like to be left alone, because of the situation that occurred at the moment of the news about my mother's death; the team should always call more than one person to talk to about it; it is difficult to receive news of death and immediately afterwards start talking about organ donation (F1).

Another experience expressed by family members refers to the interview conducted by professionals involved in the process, and doubts raised by the relatives about the complexity of the characteristics of brain death and the diagnosis of coma: [...] about six doctors talked with us whenever we were at the hospital there, different doctors spoke with us (F2) [...] at that moment, when they said they would pull the plug off, I was desperate, I was very angry, but I had doubt if my mother was really dead, because she had pink lips and her heart was beating; I know that neurologists explained to me that because of the brain stroke, my mother's brain exploded and was hopeless (F1) [...] physicians had already warned us that the situation was serious; all the time the doctor was saying about several possibilities, that she could live, she was deeply sedated, in an induced coma; they were withdrawing the medication to see if she was responding. She could keep some trauma, sequelae and, if we believe in something higher, superior, to reverse the situation and improve her condition, without sequelae, or she also could die (F4).

In some cases, prior to giving permission for the donation, there was still hope experienced by the relatives that the potential donor could have a reverse in the clinical condition expressed by the physician [...] is a difficult time, because we had hope that she would be fine, would recover. She was hospitalized since early December, and this day the brain death happened, we still had positive expectations (F5) [...] so we had hope, because hope is the last to die, all the time we expected everything would be fine (F4).

When asked about information on the donation process and the care received from the multidisciplinary team that attended the organ donor, the family members expressed that they felt happy with the information they received, emphasizing the care of the nursing professionals: [...] The affection of the procurement team, when we met them at the hospital, at the place the organ harvest would occur. We were waiting for the team. The nurses allowed us to stay until the bath time, then, we left. I found it a very warm care provided by the procurement team, they explained everything, gave us so much attention; what they did was gratifying (F5) [...] health professionals are technical, are educated, and we have to trust them, because if not, who can we trust? (F1) [...] the nurses, when I got to the hospital, they said he was bad. They, physicians, called us, then I got there into the hospital where he was transferred, and the physician got the papers and said he was grave; he had to wait for the test results. The nurses were very supportive (F7).

\section{Feelings after providing consent for organ donation}

Other content expressed by relatives that reinforced the objectives of the study included the feelings expressed after the consent for organ donation of their loved ones. The five relatives who refused to participate in the study claimed emotional difficulties in talking about the consent for donation. The other family members also expressed their feelings, as can be seen in the following statements: [...] we did not receive any support of any service or professional. If we had been followed up on by the hospital, where we donated, because we are living through this difficult time, when we needed an appointment until we are better able to deal with the pain of losing a child (F7) [...] ah, and after the organ donation; I think we should have a government support, we needed that. I think the SUS (Unified Health System - NHS-SUS) should provide assistance and the support of a psychologist. We can encourage other families who are going through it and say, you can donate, because you will receive all the support and government aid (F6) [...] in our family, we had many psychological problems. Because it's difficult to have this kind of follow up from the SUS, I think. Usually, we do not have health insurance, it is complicated (F5) [...] as suggestion, the SUS should have some kind of followup for relatives of organ donors, who pass through all this pain, anguish, alone. The needy families often cannot afford psychological support, together with social assistance to see them through the most critical point as a family of an organ donor (F4).

\section{Discussion}

The central theme of this study was the feeling of family members when facing an organ donation. Despite the complexity of the issue, organ donation has become more emphasized through the structuring of the national transplant policy. The Unified Health System (NHS-SUS) as a public policy seeks to concretely strengthen new demands that arise in the health field, in its multiple dimensions, as a social question. In accordance with the established technical regulation, the Ministry of Health has also invested in empowering the procurement teams to improve the donation rates. 
Aiming to expand social awareness of the population about the importance of organ donation, the Organ Procurement Organizations (OPOs) are using the organ donor language, bringing provocations within the Brazilian family, fostering discussions among its members about the possibility of organ donation. Despite all standardization and regulation of procedures for procurement, allocation and distribution of organs, a gap remains in the process related to the desires of the relatives of the organ donor.

The international literature ${ }^{(15-17)}$, dedicated to the subject of exploring the experiences and needs of the relatives of organ donors during and after organ donation, has shown the factors that interfere in this process.

Some authors emphasized the families' experiences of driving the donation process, found that families claimed insufficient emotional support associated with lack of clear information after the brain death of their loved ones. In another outcome, the religious influence was considered as a motivation and supporting factor for families after the consent for organ donation(17-19).

The very concept of brain death is complex and difficult to understand by people around the world and, consequently, the team should consider the social and cultural aspects of the relatives at the moment of news of this diagnosis. Enhancing the time spent with the family for clarification of brain death, and during communication of clinical developments, combined with the humanizing actions of the procurement team, seem to facilitate the positive decision of the family $y^{(15,19)}$.

The urgent hospitalization of a loved one, by itself, brings a direct impact on family dynamics, especially in the case of serious and imminent risk of death; this fact can trigger an emotional imbalance in the family. In this delicate moment, it is necessary that the physician understands the need to dedicate some time to family to assimilate the facts involving the potential donor.

The consent for organ donation means that the family members have accepted the death of the loved one, but often, they still have doubts about the diagnosis, hoping for a reversal of symptoms. These ambiguous feelings expressed by relatives were reported in the literature (20-22), and were associated with a lack of understanding of the differences between a diagnosis of brain death and coma, as the potential donor heartbeat is maintained. It seems essential that the procurement teams offer clinical information and psychological support to the family at the moment of communicating about brain death, according to individual needs.
Some authors ${ }^{(21-22)}$ suggest increased magnification in qualitative research involving this subject, seeking the support of religious leaders, and promoting actions that contribute to the satisfaction of relatives who experience the donation process.

Advances have occurred in the health care family model and the related actions, to the extent that the family unit is established as the main focus of attention and comprehensive care, attending to multiple dimensions of health, acting in the territory of the individual; thus, expanded links were established with families, and greater co-responsibility could be promoted between the health professionals and the public.

The communication with the relatives on the test results used in procurement programs, and required by the law for other centers, for the confirmation of brain death was not enough to clarify the doubts of relatives - inherent to this process - who claimed there was insufficient time between the receipt of information from the physician and the interview for donation.

The relationship between health staff and the donor's family seems to be an important indicator of the donation process. Although families authorized the donation of organs, some misconduct was described: excess of professionals addressing the relatives; the time between the notification of death and the request for donation; an inappropriate place for interview with the family. This kind of conduct should be avoided (20). In this regard, the involvement of professional social workers and psychologists can be a way to identify possible social problems of families, and to encourage the welcoming of the families throughout the process. It was also emphasized by some authors ${ }^{(22-23)}$ that government agencies should invest more in vocational training of professionals of OPOs for acting in this context.

The support provided by nurses is a satisfying factor referred to by relatives, in contrast to the literature describing an attitude of disinterest of procurement professionals for clarifying the relatives' doubts after the consent for organ removal ${ }^{(15,19,23)}$.

During the hospital stay of the potential donor, the procurement team members maintain direct contact with the relatives, with whom they are simply establishing links. Therefore, at the time of loss, it is important to provide psychological assistance to the family, to minimize suffering, preparing them for a gradual acceptance of the unexpected death of their loved one. In this sense, care for the grieving family was indicated by some authors ${ }^{(23-24)}$, since the sudden 
death of a relative is able to generate reactions of shock and perplexity in family members, jeopardizing the psychosocial context, daily activities and work.

The literature also indicates situations in which relatives claimed less conflict regarding the consent for organ donation, because they knew in advance the will of the donor. Professionals of the Organ Procurement Organization offered social assistance and emotional support to the relatives during the process and one week after the organ donation; this initiative was considered by relatives to lend to an attitude of satisfaction for having authorized the organ donation, and the relatives informed the procurement staff of a feeling of relief, by the fact that they could verbalize their experiences in the process(24-25). Campaigns about organ donation issues must be encouraged, and should be discussed by families at home.

These findings contributed to the identification of a limitation in the caring capacity of the health service, leaving the responsibility for actions to improve the conditions of access to the service to the managers.

Because of the current family refusal rates in organ donation, new strategies need to be implemented to enable advances in this process, with the establishment of integrated work process among hospital procurement professionals and the primary care network to provide adequate support for family members after donation.

\section{Conclusion}

The study identified the need to provide major social-emotional support to the relatives of potential organ donors, based on their experience of the donation process. From these findings, other practices in health care management must be approached to impact the strengthening of family ties post-donation as well as organ procurement rates.

\section{Acknowledgements}

To the families of organ donors, for their participation in this study.

\section{References}

1. Fernandes MEN, Soares MA, Boin IF, Zambelli HJ. Efficacy of social worker role in cornea donation in two different periods. Transplant Proc. 2010;42(10):3927-8. 2. Berntzen $H$, Bjørk IT. Experiences of donor families after consenting to organ donation: A qualitative study.
Intensive Crit Care Nurs. [Internet].2014. [acesso 31 jun 2014] 1-6. Disponível em: http://dx.doi.org/10.1016/j. iccn.2014.03.001.

3. Matesanz R. The Spanish national transplant organization reached a record of 4,279 transplants in 2013. [acesso 31 jun 2014] Spain Today, 2014 Feb 12. Disponível em: http://marcaespana.es/en/espana-al$\mathrm{dia} / 348 /$ the-spanish-national-transplant-organizationreached.

4. Associação Brasileira de Transplante de Órgãos. Dados numéricos da doação de órgãos e transplantes realizados por estado e instituição no período: janeiro/setembro 2014. RBT. Registro Brasileiro de Transplantes [Internet] 2014 [acesso 31 jun 2014] 20(3). Disponível em: http:// www.abto.org.br/abtov03/upload/file/RBT/2014.

5. Bramstedt KA. Family refusals of registered consents: the disruption of organ donation by double-standard surrogate decision-making. Intern Med J. 2013;43:120-3. 6. Kinrade T, Jackson AC, Tomnay J. Social workers' perspectives on the psychosocial needs of families during critical illness. Soc Work Health Care. 2011;50(9):661-81. 7. Fernandes MEN, Zambelli HJ, Boin IFSF, Oliveira MA, Zutin N, Gasparoni ARF et al. New challenges for social workers in approaching potential tissue and organ donor families in a public university hospital. Organs, Tissues, and Cells. 2008;(1)11-13.

8. Lima AAF, Silva MJP, Pereira LL. Sufrimiento y contradicción: el significado de la muerte y del morir para los enfermeros que trabajan en el proceso de donación de órganos para trasplante. Enferm Global. [Internet]. 2009. [acesso 11 ago 2014]; 15:1-17. Disponível em: http://www.revistas.um.es/eglobal/ article/view/49521/47371.

9. Topbas M, Türkyilmaz S, Can G, Ulusoy S, Kalyoncu M, Kaynar K, et al. Information, attitude, and behavior toward organ transplantation and donation among health workers in the eastern Black Sea region of Turkey. Transplant Proc. 2011;43(3):773-7.

10. Irving MJ, Tong A, Jan S, Wong G. Cass A, Chadban $S$, et al. Factors that influence the decision to be an organ donor: a systematic review of the qualitative literature. Nephrol Dial Transplant. 2012;(6):2526-33.

11. Ghorbani F, Khoddami-Vishteh HR, Ghobadi O, Shafaghi S, Louyeh AR, Najafizadeh K. Causes of family refusal for organ donation. Transplant Proc. 2011;43(2):405-6.

12. Marck CH, Neate SL, Skinner M, Dwyer B, Hickey B, $D^{\prime}$ Costa $R$, et al. Factors relating to consent for organ donation: prospective data on potential organ donors. Intern Med J 2015;45(1)40-7. 
13. López Martínez JS, Martín López MJ, Scandroglio B, Martínez García JM. Family perception of the process of organ donation. Qualitative psychosocial analysis of the subjective interpretation of donor and nondonor families. Span J Psychol. 2008;11(1):125-36.

14. Campos CJG, Turato ER. Content analysis in studies using the clinical-qualitative method: application and perspectives. Rev. Latino-Am. Enfermagem. 2009;17(2):259-64.

15. Yousefi $H$, Roshani A, Nazari F. Experiences of the families concerning organ donation of a family member with brain death. Iran J Nurs Midwifery Res. 2014;19(3):323-30.

16. Manzari ZS, Mohammadi E, Heydari A, Sharbaf HR, Azizi MJ, Khaleghi E. Exploring families' experiences of an organ donation request after brain death. Nurs Ethics. 2012; 19(5):654-65.

17. Manuel A, Solberg S, MacDonald S. Organ donation experiences of family members. Nephrol Nurs J. 2010;37(3):229-36.

18. Tawil I, Brown LH, Comfort D, Crandall CS, West SD, Rollstin $A D$, et al. Family presence during brain death evaluation: a randomized controlled trial. Crit Care Med. 2014; 42(4):934-42.

19. Kim HS, Yoo YS, Cho OH. Satisfaction with the organ donation process of brain dead donors' families in Korea. Transplant Proc. 2014;46(10):3253-6.

20. Walker W, Broderick A, Sque M. Factors influencing bereaved families' decisions about organ donation: an integrative literature review. West J Nurs Res. 2013;35:1339-59.

21. Stouder DB, Schmid A, Ross SS, Ross LG, Stocks L. Family, friends, and faith: how organ donor families heal. Prog Transplant. 2009;19(4):358-61.

22. Neate $S L$, Marck $C H$, Skinner M, Dwyer B, McGain $\mathrm{F}$, Weiland $\mathrm{TJ}$, et al. Understanding australian families' organ donation decisions. Anaesth Intensive Care. 2015;43(1):42-50.

23. Jacoby L, Crosier V, Pohl H. Providing support to families considering the option of organ donation: an innovative training method. Prog Transplant. 2006;16(3):247-52.

24. Anker AE, Akey JE, Feeley TH. Providing social support in a persuasive context: forms of social support reported by organ procurement coordinators. Health Commun. 2013;28(8):835-45.

25. Satoh A. Care and support for organ donor families. Japan Med Assoc J. 2011;54(6):392-7. 